Article

\title{
Development of Injectable Thermosensitive Chitosan-Based Hydrogels for Cell Encapsulation
}

\author{
Antonella Stanzione ${ }^{1,2}$, Alessandro Polini ${ }^{2}{ }^{\circ}$, Velia La Pesa ${ }^{3}$, Alessandro Romano ${ }^{3}$, \\ Angelo Quattrini ${ }^{3}{ }^{\mathbb{D}}$, Giuseppe Gigli ${ }^{1,2}$, Lorenzo Moroni ${ }^{2,4}{ }^{\mathbb{D}}$ and Francesca Gervaso ${ }^{2, *}$ \\ 1 Dipartimento di Matematica e Fisica E. De Giorgi, University of Salento, 73100 Lecce LE, Italy; \\ antonella.stanzione@unisalento.it (A.S.); giuseppe.gigli@unisalento.it (G.G.) \\ 2 CNR-Nanotec, Institute of Nanotechnology, 73100 Lecce, Italy; alessandro.polini@nanotec.cnr.it (A.P.); \\ 1.moroni@maastrichtuniversity.nl (L.M.) \\ 3 IRCCS San Raffaele Scientific Institute, Neuropathology Unit, Institute of Experimental Neurology and \\ Division of Neuroscience, 20132 Milan, Italy; lapesa.velia@hsr.it (V.L.P.); romano.alessandro@hsr.it (A.R.); \\ quattrini.angleo@hsr.it (A.Q.) \\ 4 Complex Tissue Regeneration, Maastricht University, 6229 ER Maastricht, The Netherlands \\ * Correspondence: francesca.gervaso@nanotec.cnr.it; Tel.: +39-083-231-9305
}

Received: 27 July 2020; Accepted: 17 September 2020; Published: 19 September 2020

Featured Application: The developed thermoresponsive injectable hydrogels might be used as cell-delivery systems, 3D matrices for cell culture study, drug screening platforms, and for regenerative medicine applications.

\begin{abstract}
The three-dimensional complexity of the native extracellular matrix (ECM) suggests switching from 2D to 3D culture systems for providing the cells with an architecture more similar to the physiological environment. Reproducing the three-dimensionality in vitro can guarantee beneficial effects in terms of cell growth, adhesion, proliferation, and/or their differentiation. Hydrogels have the same tailorable physico-chemical and biological characteristics as ECM materials. In this study, we propose a thermoresponsive chitosan-based hydrogel that gels thanks to the addition of organic and inorganic salt solutions (beta-glycerolphosphate and sodium hydrogen carbonate) and is suitable for cell encapsulation allowing obtaining 3D culture systems. Physico-chemical analyses showed that the hydrogel formulations jellify at physiological conditions $\left(37^{\circ} \mathrm{C}, \mathrm{pH} 7.4\right)$, are stable in vitro up to three weeks, have high swelling ratios and mechanical stiffness suitable for cellular encapsulation. Moreover, preliminary biological tests underlined the pronounced biocompatibility of the system. Therefore, these chitosan-based hydrogels are proposed as valid biomaterials for cell encapsulation.
\end{abstract}

Keywords: stimuli-responsive hydrogel; natural polymers; cell encapsulation; in vitro degradation; swelling ratio; injectable hydrogel; 3D matrices; biocompatibility

\section{Introduction}

In traditional cell culture systems, glass and polystyrene are the commonly used materials for cell growth in two-dimensional (2D) systems [1]. However, the native environment where cells live and carry out their functions is three-dimensional (3D) and this spatial organization strongly influences cell behavior through the mutual exchange of chemical and physical signals between cells and their microenviroment [2,3]. Although 2D cell culture systems have been and are still fundamental for studying many cellular processes, they are too simplified for capturing most of the physiological functions and interactions of several biological tissues and organs. Many in vitro 
studies showed the importance of 3D architectures in many cellular processes, such as cell migration and differentiation [4,5]. 3D culture systems were successfully proposed as disease models, useful to evaluate in vitro the effects of drugs or build tissue analogous for regenerative medicine and tissue engineering applications [6,7]. In recent years, the role of biomaterials has gone beyond the conventional vision of a passive support for cell growth [8]. The increasing knowledge of the wide range of interactions between matrices and cells drove scientific interest toward the development of biomaterials able to mimic spatial-temporal signals of the ECM [9]. The biomaterial, besides meeting the fundamental requirements of biocompatibility, biodegradability, and porosity, must also be able to interact with specific cell types, for example displaying ad hoc mechanical properties and "active" surface characteristics capable of guiding the desired cellular processes [10,11]. The similarity between the composition of the ECM and some natural or synthetic polymers is the basis of the development of so-called hydrogels used in 3D culture systems. A hydrogel is defined as "a three-dimensional hydrophilic polymer network capable of absorbing and retaining large amounts of water or biological fluids" [12]. Based on their material of origin, hydrogels can be classified as natural or synthetic [13], and divided into two further groups based on the type of crosslinking, chemical or physical, which influences hydrogel physical properties and the irreversible or transient nature of polymer chain interaction [14,15]. Moreover, stimuli-responsive hydrogel systems can be designed by integrating specific functional groups, responsive to different stimuli such as $\mathrm{pH}$, temperature, magnetic or electric field, and bioactive molecules [16]. Among them, the physiological body temperature acting as a trigger for inducing the sol-gel transition appears to be a very promising strategy, especially for biomedical uses. They can swell in situ under physiological conditions and provide the advantage of being conveniently administered. Typically, aqueous solutions of hydrogels used in biomedical applications are liquid at room temperature (RT) (injectable hydrogel) and gel at physiological temperature [17]. In this regard, injectable hydrogels have important properties such as being minimally invasive for the body as well as able to retain large quantities of water. Moreover, the three-dimensional and porous structure of such hydrogels make an ideal network, which holds the cells in place while allowing the transport of nutrients, wastes, and other essential molecules [18]. Although several synthetic polymers, such as PVA, PEG and PLA $[19,20]$, have been proposed in this context for hydrogel preparation, natural polymers have shown higher biocompatibility and physical match to the ECM compared to the synthetic ones [21]. Polymers such as hyaluronic acid [22], chitosan [23], gelatin, fibrinogen [24], collagen [25], and alginate [26] can be further modified to induce specific and desired biological reactions Among the above-mentioned natural polymers, chitosan-based hydrogels are presently being widely used due to their well-documented biocompatibility, low toxicity and degradability by human enzymes [27]. Chitosan is a linear polysaccharide derived from chitin, extracted from the crustacean exoskeleton [28], and characterized by marked biocompatibility and biodegradability properties. Chitosan temperature-controlled gelation can be easily obtained by adding beta-glycerol-phosphate to the system (BGP) [21-29]. BGP prevents the precipitation of chitosan and induces its sol-gel transition when the temperature is increased in the range $32-37^{\circ} \mathrm{C}$, i.e., compatible with cell viability. [29]. BGP also allows to obtain a gel with a physiological $\mathrm{pH}$, and therefore suitable for cell encapsulation. Moreover, such hydrogel systems are softer and less cytotoxic compared to gels formed by chemical modification [2]. Few studies have shown that chitosan can also thermogel in the presence of other weak bases, such as sodium hydrogen carbonate (SHC) [30], but the obtained hydrogels did not present rapid gelation and appropriate mechanical properties. Assaad et al., however, demonstrated that a very interesting synergic effect can be reached combining SHC with BGP, obtaining hydrogels with rapid gelation and improved mechanical properties, despite even lowered salt concentrations as compared to CH:BGP hydrogels [31]. In the present study, SHC and L-arginine (ARG), a dibasic amino acid fundamental in cellular physiology [32], were introduced in a BGP hydrogel system with the aim of enhancing the in vitro performance in terms of stability and mechanical properties of thermoresponsive chitosan-based hydrogels with a sol-gel transition at $37^{\circ} \mathrm{C}$ and at physiological $\mathrm{pH}$, tested as 3D cell culture systems. L-Arg is a conditionally essential amino acid, involved as a precursor 
in many important biochemical pathways in cellular physiology (i.e., nitric oxide pathway involved in nerve regeneration) [33-35], and therefore an enhancer of some key cell processes, e.g., collagen synthesis, T-cell mediated responses, and also the release of pituitary hormones [36]. For these reasons, in our previous studies [37-39], we used it as a non-toxic ionic cross-linking biomolecule for chitosan structures, hopefully eliciting enhanced biological responses. The results showed that ARG was able to improve the in vitro stability of chitosan 3D structures, such as scaffolds and electrospun membranes. In the present work, we aim at verifying if ARG could give a similar contribution even in chitosan hydrogel systems. The hydrogel systems have been characterized in terms of injectability and gelation, in vitro swelling ratio and stability and mechanical properties. Finally, preliminary biological tests have been performed to investigate the suitability of the developed hydrogels for encapsulation of a neuronal-like cell type.

\section{Materials and Methods}

\subsection{Chitosan Hydrogel Preparation}

Low molecular weight chitosan (Sigma Aldrich, Milan, Italy) was used for hydrogel preparation. The hydrogel was prepared starting from a 3.3\% (w/v) solution of chitosan (CS) in $0.1 \mathrm{M} \mathrm{HCl}$ (Sigma Aldrich, Milan, Italy). The solution was kept under stirring at RT overnight. The gelling agent (GA) solutions were prepared by dissolving BGP, SHC, ARG powders in milliQ water to a final concentration of $0.2 \mathrm{M}, 0.05 \mathrm{M}, 0.01 \mathrm{M}$ for BGP, SHC and Arg, respectively (see Table 1). The CS and GA solutions were mixed in the ratio of 3:2 by using two syringes joined by a female-to-female Luer Lock connector. Immediately after mixing, hydrogels were injected into custom-made molds and placed in an oven at $37^{\circ} \mathrm{C}$ for $2 \mathrm{~h}$, in order to thermally induce the sol-gel transition. The $\mathrm{pH}$ values of the CS, GA, and $\mathrm{CS}+\mathrm{GA}$ solutions were monitored by a $\mathrm{pH}$-meter both after solution preparation and mixing. Three different hydrogel formulations have been studied and characterized: CS+SHC, CS+SHC+BGP, $\mathrm{CS}+\mathrm{SHC}+\mathrm{BGP}+\mathrm{ARG}$.

Table 1. Initial and final concentration of GA and $\mathrm{CH}$ solutions. $\mathrm{pH}$ values of GA solutions (before mixing) and hydrogels (after mixing).

\begin{tabular}{ccccc}
\hline $\begin{array}{c}\text { GA } \\
\text { Solution/Hydrogels }\end{array}$ & $\begin{array}{c}\text { Initial } \\
\text { Concentration }\end{array}$ & Initial $\mathbf{p H}$ & $\begin{array}{c}\text { Final Concentration } \\
\text { in Hydrogel }\end{array}$ & Final pH \\
\hline BGP & $0.5 \mathrm{M}$ & 8.6 & $0.2 \mathrm{M}$ & - \\
BGP & $0.75 \mathrm{M}$ & 8.6 & $0.2 \mathrm{M}$ & - \\
BGP & $1.5 \mathrm{M}$ & 8.6 & $0.2 \mathrm{M}$ & - \\
SHC & $0.375 \mathrm{M}$ & 8.5 & $0.05 \mathrm{M}$ & - \\
$\mathrm{Arg}$ & $0.075 \mathrm{M}$ & 5.5 & $0.01 \mathrm{M}$ & - \\
$\mathrm{CH}$ & $3 \%$ & 5.5 & $2 \%$ & - \\
$\mathrm{CH}+\mathrm{SHC}$ & - & - & - & 7.4 \\
$\mathrm{CH}+\mathrm{SHC}+\mathrm{BGP}$ & - & - & - & 7.2 \\
$\mathrm{CH}+\mathrm{SHC}+\mathrm{BGP}+\mathrm{Arg}$ & - & - & - & \\
\hline
\end{tabular}

\subsection{Injectability and Gelation Time}

Hydrogels injectability was evaluated at RT by injecting CS-GA immediately after mixing using syringes equipped with a $23 \mathrm{G}$ needle. Gelation kinetics was evaluated by the inversion tube test. The hydrogel was kept at $37^{\circ} \mathrm{C}$ and the "sol" or "gel" state has been determined through visual inspection by inverting the tube every $5 \mathrm{~min}$. Gelation was established by the state of flowing and not-flowing as the tube was inverted [20]. Moreover, the gel state was also confirmed by rheological studies (see Supplemetary Materials). 


\subsection{Swelling Ratio and Stability Test}

The swelling test was carried out by soaking the hydrogel, previously freeze-dried, in a PBS solution at $37^{\circ} \mathrm{C}$. The samples were weighted before $\left(\mathrm{W}_{\mathrm{dry}}\right)$ and after $\left(\mathrm{W}_{\text {wet }}\right)$ hydration in PBS at different time points: 10,20,30 min and 1,2,6,24, and $48 \mathrm{~h}$. The swelling ratio percentage (SR) has been calculated according to the following Formula (1):

$$
\text { SR }(\%)=[(\text { Wwet }- \text { Wdry }) / \text { Wdry }] \times 100
$$

To assess the hydrogel stability in physiological conditions, a not enzymatic in vitro degradability test was performed by monitoring, at several time points, the weight loss of the hydrogels immersed in PBS. The weighs were recorded at 1, 2, 6, 24, 48, $96 \mathrm{~h}$. The percentage of weight loss (WL) was calculated as (2):

$$
\mathbf{W L}(\%)=(\mathbf{W} 0-\mathbf{W i}) /(\mathbf{W} 0) \times 100
$$

where $\mathrm{W}_{0}$ is the weight of hydrogel after thermal gelation at $37^{\circ} \mathrm{C}$ and $\mathrm{W}_{\mathrm{i}}$ is the weight at the different selected time points.

\subsection{Compression Test}

The hydrogel stiffness was evaluated through an unconfined compression test. The hydrogel samples were tested after $2 \mathrm{~h}$ of gelation at $37^{\circ} \mathrm{C}$ in hydrated condition using a petri dish filled by PBS as compression plate. The compression tests have been conducted at RT. using a universal testing machine (ZwickiLine 1kN, Zwick Roell, Kennesaw, GA, USA), equipped with a $10 \mathrm{~N}$ load cell, up to $75 \%$ deformation and with a displacement velocity of $2 \mathrm{~mm} / \mathrm{min}$ (ZwickiLine $1 \mathrm{kN}$, Zwick Roell, Kennesaw, GA, USA). The average Young's modulus (E) was calculated as the slope of the linear elastic region of the stress-strain curve at low strain values (in the range $0-5 \%$ ).

\subsection{Cell Culture and Cell Embedding Within Hydrogels}

SH-SY5Y neuroblastoma cells were cultured in Dulbecco's Modified Eagle Medium (DMEM) with $2 \mathrm{mM}$ of glutamine (Corning) supplemented with $10 \% \mathrm{FBS}, 100 \mathrm{U} / \mathrm{mL}$ penicillin and $100 \mu \mathrm{g} / \mathrm{mL}$ streptomycin (Corning). Cells were incubated at $37{ }^{\circ} \mathrm{C}$ with $95 \%$ of humidity and $5 \%$ of $\mathrm{CO}_{2}$. After preliminary tests, a density of 2 million cells per $\mathrm{mL}$ of hydrogel was chosen for encapsulation, by gently mixing the cell suspension into the hydrogel solution. Two million cells, resuspended in $166 \mu \mathrm{L}$ of DMEM, were encapsulated in $1 \mathrm{~mL}$ of hydrogel. The cell-laden hydrogel was incubated at $37^{\circ} \mathrm{C}$ with $95 \%$ humidity and $5 \% \mathrm{CO}_{2}$ for $24 \mathrm{~h}$ in the presence of DMEM.

\subsection{Cytotoxicity Assay: 3-(4,5-dimethylthiazol-2-yl)-2,5-diphenyltetrazolium bromide (MTT) Assay}

An indirect viability test was performed to test the hydrogel biocompatibility. SH-SY5Y cells were cultured in their medium in a 48 multiwell plate at a final concentration of 30,000 cells per well. When cells reached $80 \%$ confluency, the culture medium was removed and substituted with either fresh SH-SY5Y medium (positive control) or conditioned medium, i.e., DMEM placed in contact for 24, 48 and $72 \mathrm{~h}$ with the hydrogel preparations. After $24 \mathrm{~h}$, the MTT assay was performed following the manufacturer's instructions (Sigma Aldrich, Milan, Italy). The supernatant was removed and replaced with 500 microliters of MTT solution ( $5 \mathrm{mg} / \mathrm{mL}$ in PBS) and the plate was incubated at $37^{\circ} \mathrm{C}$ for $3 \mathrm{~h}$. Afterward, the MTT solution was discarded and $1 \mathrm{~mL}$ of isopropanol added and mixed to dissolve the formazan crystals. Absorbance was measured at $570 \mathrm{~nm}$.

\subsection{Analysis of Cell Morphology and Distribution in Hydrogel by Dapi/Phalloidin Staining}

To evaluate the cell morphology and distribution within the hydrogel CS+SHC+BGP, the cell-laden hydrogels were incubated for $24 \mathrm{~h}$ at $37^{\circ} \mathrm{C}$ and then incubated in a $30 \%$ sucrose solution in PBS 
overnight. Subsequently, the samples were frozen at $-80^{\circ} \mathrm{C}$ and cut with a cryostat. Slices with a thickness of 25 um were obtained by cutting the sample longitudinally and transversely throughout its thickness. The slices were subjected to Dapi/Phalloidin staining according to the following protocol: slices were fixed in 4\% PFA in PBS, permeabilized with Triton X-100 in PBS, incubated with 1\% BSA in PBS, stained with Phalloidin in BSA (1:1000 v/v) at $1 \%$ in PBS, finally incubated with Dapi solution in PBS $(1: 10,000 \mathrm{v} / \mathrm{v})$. The samples were then observed by fluorescence microscopy (Evos m5000 fluorescent microscope, Olympus BX-61 microscope) and confocal microscopy (Leica TCS SP8 STED) and then stored at $4{ }^{\circ} \mathrm{C}$.

\subsection{Live/Dead Staining on Cell-Laden Hydrogels}

The live and dead assay was performed in order to evaluate the viability of the SHSY5Y cells encapsulated within the hydrogel, as described in Section 2.5. $250 \mu \mathrm{L}$ drops of cell-embedded hydrogel were incubated and the cell viability was evaluated $10 \mathrm{~min}$ immediately after cell encapsulation $(t=$ $10 \mathrm{~min})$, and after $24 \mathrm{~h}(t=24 \mathrm{~h})$, accordingly to the following protocol. The working solution was prepared by adding $1.25 \mu \mathrm{L}$ of stock solution of Calcein-AM $(1 \mathrm{mM})$ and $50 \mu \mathrm{L}$ of stock solution of Propidium Iodide (PI, $2 \mathrm{mg} / \mathrm{mL}$ ) into $5 \mathrm{~mL}$ of pre-warmed PBS. The cell-encapsulated hydrogel drops were deprived of culture medium, washed three times in PBS, completely covered by working solution and finally incubated for $1 \mathrm{~h}$ and protected from light. At the end of incubation, the working solution was removed, the drops were washed three times in PBS, and finally medium L15 (without phenol red and supplemented with $\mathrm{CO}_{2}$ ) was added. Fluorescence images have been obtained at $488 \mathrm{~nm}$ for Calcein-AM (live cells) and $561 \mathrm{~nm}$ for PI (dead cells).

\subsection{Statistical Analysis}

All experiments were performed in triplicate, unless otherwise stated. The results of multiple observations are presented as the mean \pm standard deviation. Statistical significance was assessed by the Student's $t$-test; values were considered significant at $p<0.05$.

\section{Results}

\section{1. $\mathrm{pH}$ Values}

The $\mathrm{pH}$ values of gelling agent (GA) and chitosan solutions were measured before and after mixing. The values reported in Table 1 show that all samples reached a physiological $\mathrm{pH}$ immediately after mixing, and are therefore suitable for cellular encapsulation.

\subsection{Hydrogel Injectability and Inversion Tube Tests}

All samples were injectable immediately after mixing at RT through a 23G needle (see Video_S1). The thermoresponsive behavior was verified by the inversion tube test. All samples stopped to flow along the vial walls a few minutes after being placed at $37^{\circ} \mathrm{C}$, indicating a rapid gelation as soon as the temperature reached $37^{\circ} \mathrm{C}$ (Figure 1). Moreover, when injected into PBS at $37^{\circ} \mathrm{C}$, all $\mathrm{CH}+\mathrm{GA}$ solutions showed the sol-gel transition forming a stable wire. Instead, no gelation occurred when the $\mathrm{CH}+\mathrm{GA}$ solutions were injected into PBS at $4{ }^{\circ} \mathrm{C}$ (Figure S1, Video_S2 and Video_S3). As shown by rheological tests (Supplementary Materials), the elastic contribution was predominant on the viscous one (material already at the gel state and not sol anymore) for all hydrogel formulations at both 21 and $37^{\circ} \mathrm{C}$. However, both storage modulus $\left(\mathrm{G}^{\prime}\right)$ and loss modulus $\left(\mathrm{G}^{\prime \prime}\right)$ are significantly higher when measured at $37^{\circ} \mathrm{C}$, confirming the thermoresponsive behavior observed in the inversion tube test. 


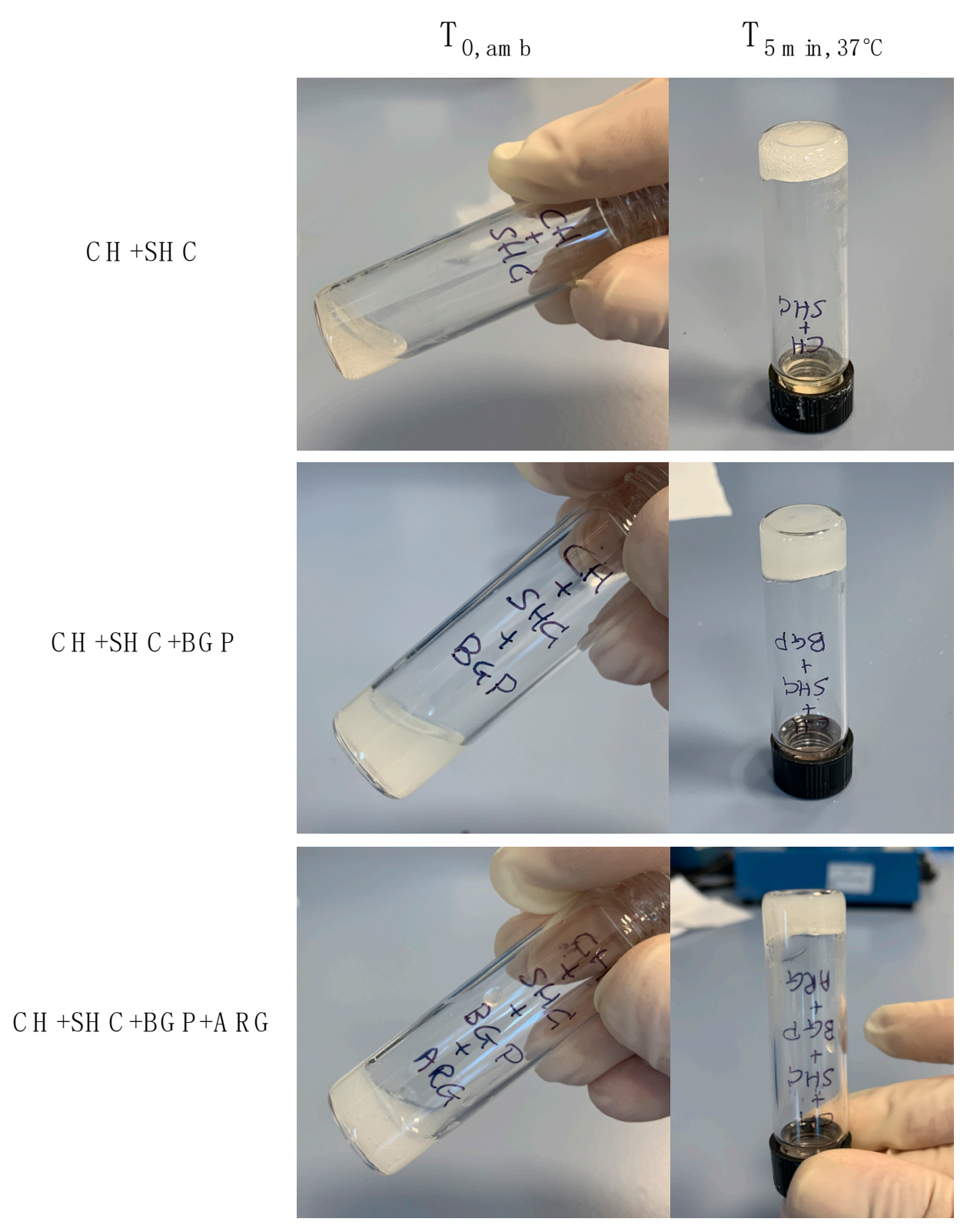

Figure 1. Inversion tube test: pictures of the three hydrogel formulations taken immediately after the mixing at RT and after $5 \mathrm{~min}$ of incubation at $37^{\circ} \mathrm{C}$.

\subsection{Swelling Ratio and Stability Tests}

For each type of sample, three freeze-dried samples were weighted before and after hydration at different time points in order to investigate their swelling properties. The swelling tests showed that all hydrogels absorbed most of the PBS solution in the first $30 \mathrm{~min}$ (SR equal to $920 \pm 302,880 \pm 92,714$ \pm 92 for $\mathrm{CH}+\mathrm{SHC}, \mathrm{CH}+\mathrm{SHC}+\mathrm{BGP}, \mathrm{CH}+\mathrm{SHC}+\mathrm{BGP}+\mathrm{ARG}$, respectively) and were able to retain the absorbed water without any release up to $48 \mathrm{~h}$ (Figure 2). The three hydrogel formulations have all very high $\mathrm{SR}$ values, although $\mathrm{CH}+\mathrm{SHC}+\mathrm{BGP}+\mathrm{ARG}$ present a $\mathrm{SR}$ significantly lower suggesting a stronger interaction among the chitosan chains due to the presence of three GAs. Moreover, the higher standard deviation of $\mathrm{CH}+\mathrm{SHC}$ samples might suggest a high inter-specimen variability. 
(a)

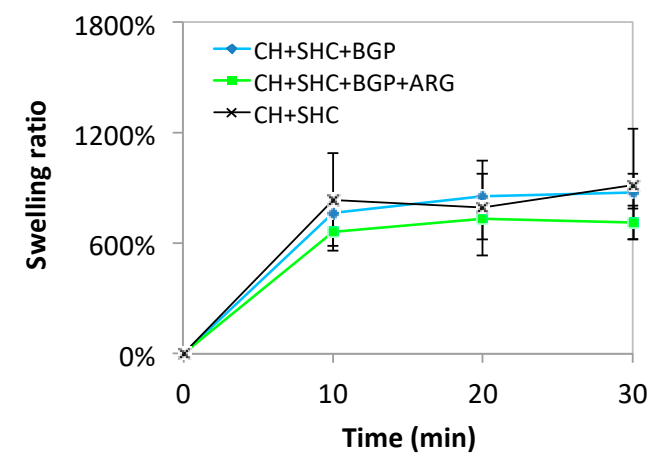

(b)

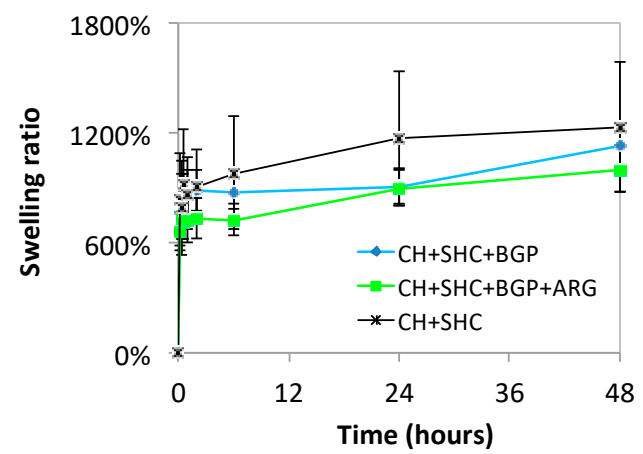

Figure 2. Swelling ratio of the three hydrogels: $\mathrm{CH}+\mathrm{SHC}, \mathrm{CH}+\mathrm{SHC}+\mathrm{BGP}, \mathrm{CH}+\mathrm{SHC}+\mathrm{BGP}+\mathrm{ARG}$ in the first $30 \mathrm{~min}$ (a) and up to $48 \mathrm{~h}(\mathbf{b})$.

The samples were weighted at different time points in order to determine their stability at the operating conditions. Hydrogels showed weight loss rapidly increasing in the first $6 \mathrm{~h}$, which reached after $24 \mathrm{~h}$ a maximum value of $21.2 \% \pm 1.5 \%$ and $23.2 \% \pm 0.7 \%$ for $\mathrm{CH}+\mathrm{SHC}$ and $\mathrm{CH}+\mathrm{SHC}+\mathrm{BGP}+\mathrm{ARG}$ that remained almost constant up to $96 \mathrm{~h}$ in PBS at $37^{\circ} \mathrm{C}$. Samples with SHC+BGP without ARG presented weight loss after $24 \mathrm{~h}$ of $23.7 \% \pm 1.7 \%$, similar to the other two hydrogel formulations that however showed a small but significantly different increase in the weight loss $(28.5 \pm 1.2 \%)$ at $48 \mathrm{~h}$, approximately constant throughout the rest of the test $(p<0.05)$ (Figure 3 ).

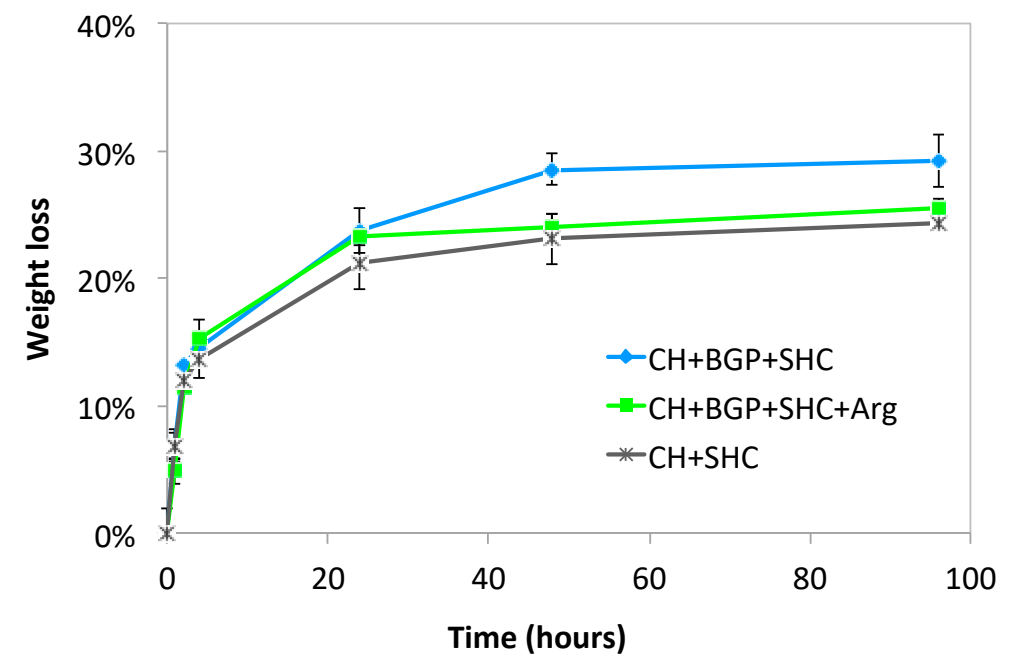

Figure 3. Stability of the three hydrogels $\mathrm{CH}+\mathrm{SHC}, \mathrm{CH}+\mathrm{SHC}+\mathrm{BGP}, \mathrm{CH}+\mathrm{SHC}+\mathrm{BGP}+\mathrm{ARG}$ up to 4 days.

\subsection{Compression Test}

Unconfined compression tests were carried out to evaluate the stiffness of the hydrogel. The stress-strain curve of all the samples showed a non-linear elastic behavior without any sign of hydrogel fracture up to $50 \%$ of strain (Figure $4 \mathrm{a}$ ). For all samples, the stiffness increased as the strain increased, showing the typical compressive stress-strain behavior of hydrogel materials [40]. However, the stress-strain curve of the $\mathrm{CH}+\mathrm{SHC}$ sample resulted significantly lower (up to 0.55 of strain) than other two hydrogel formulations. The Young modulus, calculated as the slope of the compressive stress-strain curve at low strain values $(0-5 \%)$, for $\mathrm{CH}+\mathrm{SHC}+\mathrm{BGP}$ and $\mathrm{CH}+\mathrm{SHC}+\mathrm{BGP}+\mathrm{ARG}$ resulted equal to $6.65 \pm 0.50 \mathrm{KPa}$ and $6.87 \pm 0.53 \mathrm{KPa}$ respectively, significantly higher $(p<0.05)$ than Young modulus of $\mathrm{CH}+\mathrm{SHC}$, equal to $2.61 \pm 0.43 \mathrm{KPa}$ (Figure $4 \mathrm{~b}$ ). The compression test results indicated that the addition of BGP to $\mathrm{CH}+\mathrm{SHC}$ system conferred more stiffness to chitosan hydrogels, suggesting 
that stronger interactions occur between chitosan chains in the presence of BGP salt. Addition of ARG did not induce any significant change in the hydrogel mechanical properties. Hydrogels showed a compressive stiffness in the range $2-10 \mathrm{KPa}$, range in which most of the biological soft tissues' compressive stiffness falls [41].

(a)

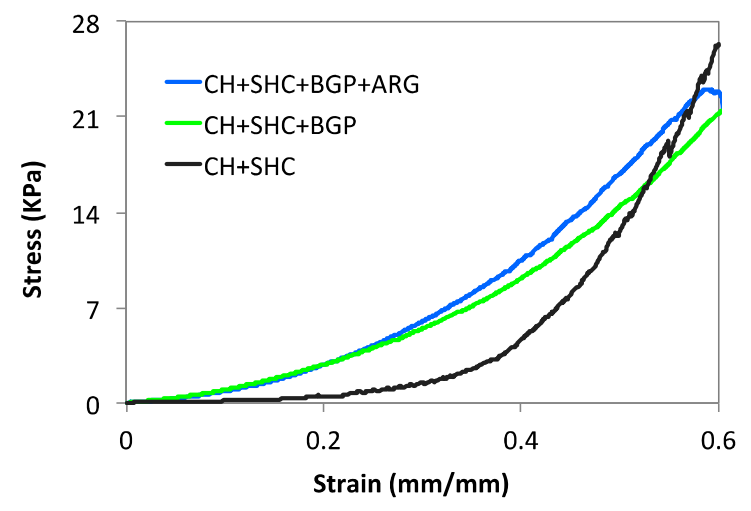

(b)

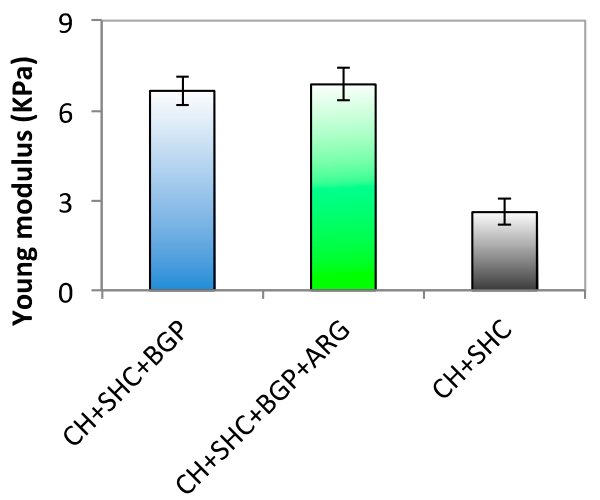

Figure 4. (a) Example of the stress-strain curves from the compression test performed on the three hydrogel formulations. (b) Young modulus of the three hydrogels $\mathrm{CH}+\mathrm{SHC}, \mathrm{CH}+\mathrm{SHC}+\mathrm{BGP}$, $\mathrm{CH}+\mathrm{SHC}+\mathrm{BGP}+\mathrm{ARG}$ (average + standard deviation, $\mathrm{n}=3$ ).

\subsection{Cytotoxicity Assay: 3-(4,5-dimethylthiazol-2-yl)-2,5-diphenyltetrazolium bromide (MTT) Assay}

Hydrogel biocompatibility was analyzed in SH-SY5Y cells by indirect toxicity test using MTT assay. Cell viability was greater than $80 \%$ compared to the control (unconditioned DMEM) for all the hydrogels formulations analyzed. These results indicate that the three different hydrogels did not release into the medium (up to $72 \mathrm{~h}$ ) any compounds or agents that can significantly affect cell survival/growth and reveal the good biocompatibility properties of these hydrogels (Figure 5).

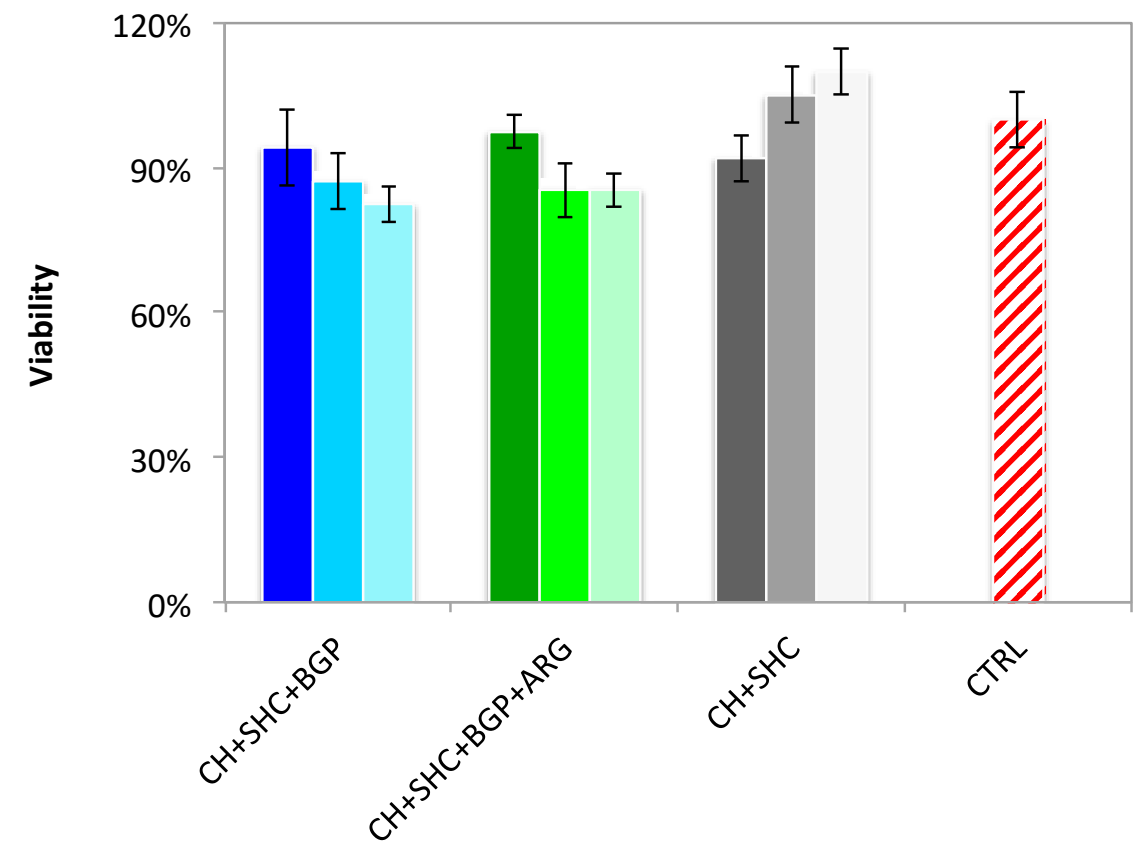

Figure 5. Viability of SH-SY5Y cells exposed for $24 \mathrm{~h}$ to medium conditioned with the three hydrogels $\mathrm{CH}+\mathrm{SHC}, \mathrm{CH}+\mathrm{SHC}+\mathrm{BGP}, \mathrm{CH}+\mathrm{SHC}+\mathrm{BGP}+\mathrm{ARG}$ for 24 (darker color), 48 (medium color), $72 \mathrm{~h}$ (lighter color). Cell viability was measured using MTT assay and data was reported as average \pm standard deviation $(n=3)$. 


\subsection{Analysis of Cell Distribution in Hydrogel by Dapi/Phalloidin Staining}

To evaluate the morphology and distribution of SH-SY5Y cells throughout the hydrogels transversal and longitudinal sections of the $\mathrm{CH}+\mathrm{SHC}+\mathrm{BGP}$ hydrogel loaded with the cells were stained for actin-phalloidin, counterstained with DAPI (nuclei), and observed under a fluorescence microscope (Figure 6a,b). SH-SY5Y cells presented a rounded shape morphology (Figure 6a) and were found to be spread over the entire surface of all the slices analyzed (Figure $6 b, c)$, indicating that the cell embedding method allowed the homogeneous distribution of the cells through the hydrogel.

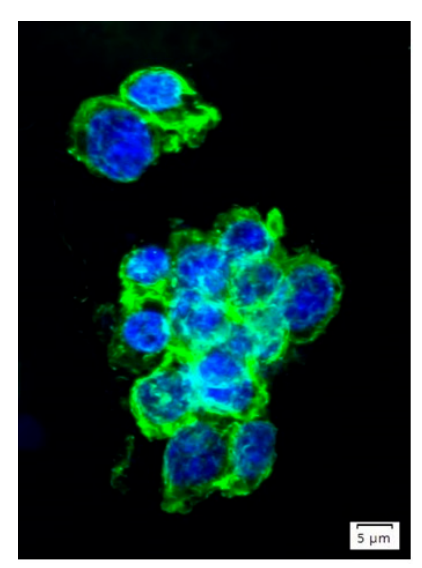

(a)
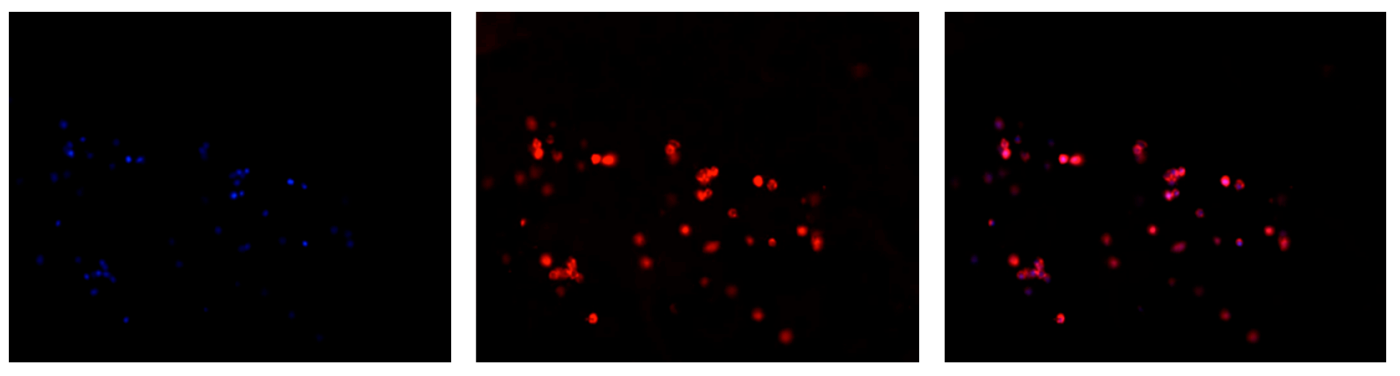

(b)
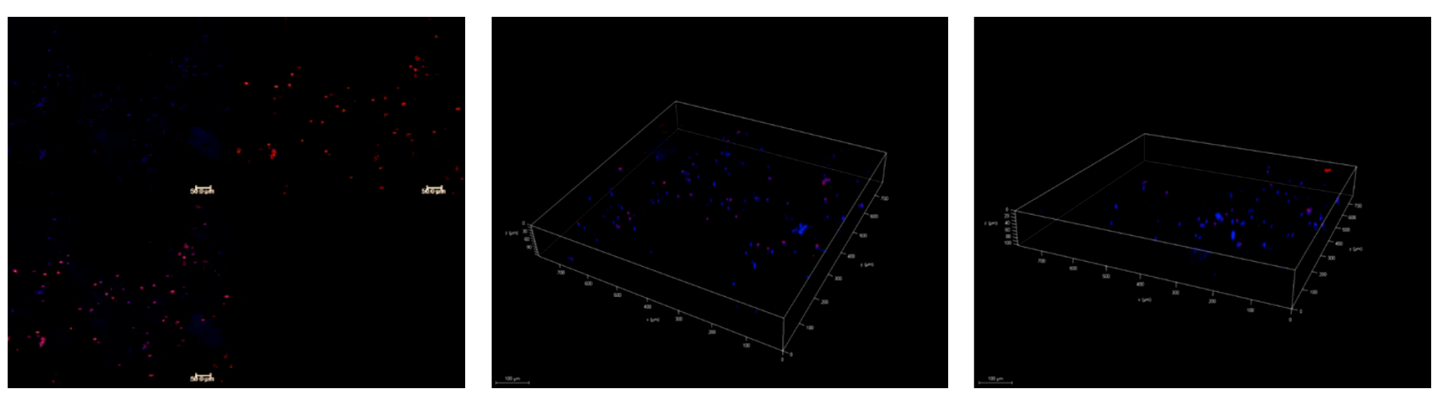

(c)

Figure 6. (a) Morphology of SH-SY5Y cells growth in the CH+BGP+SHC hydrogel for $24 \mathrm{~h}$. Cells were stained with FITC-phalloidin (green, actin filaments) and DAPI (blue, nuclei). Merged FITC/DAPI. Scale bar, $5 \mu \mathrm{m}$. (b) Low magnification images of taken after $24 \mathrm{~h}$ of SH-SY5Y embedded in CH+SHC+BGP hydrogel loaded with SH-SY5Y after $24 \mathrm{~h}$ of culture. Cells were stained with TRICT-phalloidin for actin filaments (red, left panel) and DAPI for nuclei (blue, middle panel). Right panel shows the merged image. Scale bar, $200 \mu \mathrm{m}$. (c) 3D reconstruction of cell distribution in the hydrogel (CH+BGP+SHC) sample obtained from confocal Z-stacks. 


\subsection{Cell-Embedded Hydrogel Viability through Live/Dead Staining}

The $\mathrm{CH}+\mathrm{SHC}+\mathrm{BGP}$ hydrogel system was tested by live/dead assay and the results clearly indicate that the viability of SH-SY5Y was unaffected by the presence of hydrogel components (Figure 7). Very rare red nuclei, indicating dead cells, could be detected, while numerous metabolically active cells (green colored) were imaged.
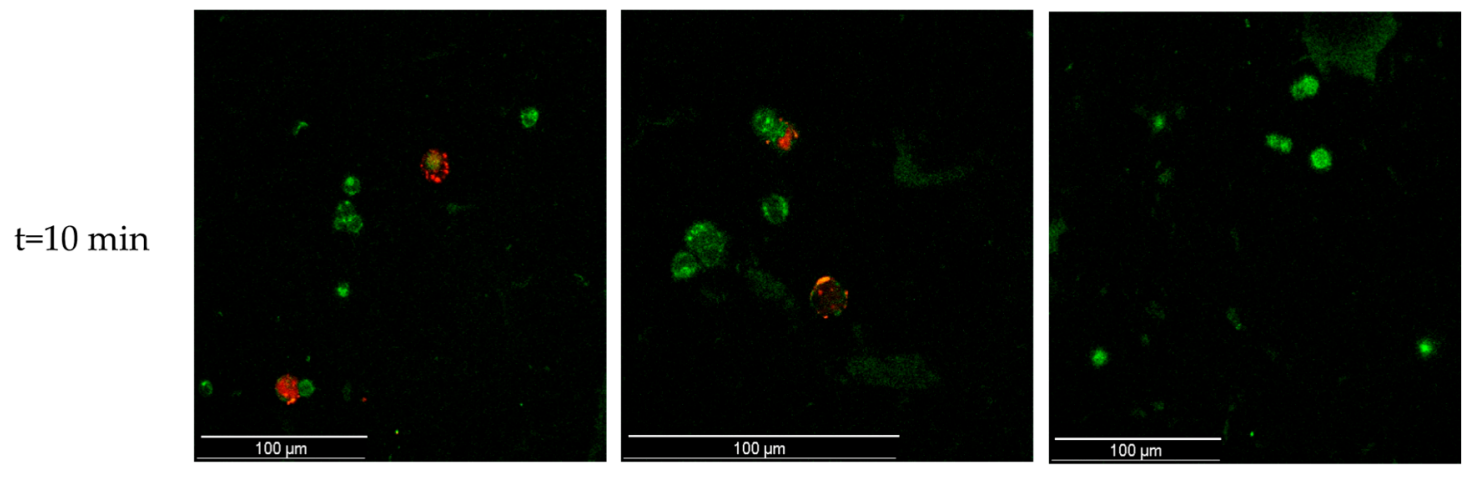

(a)
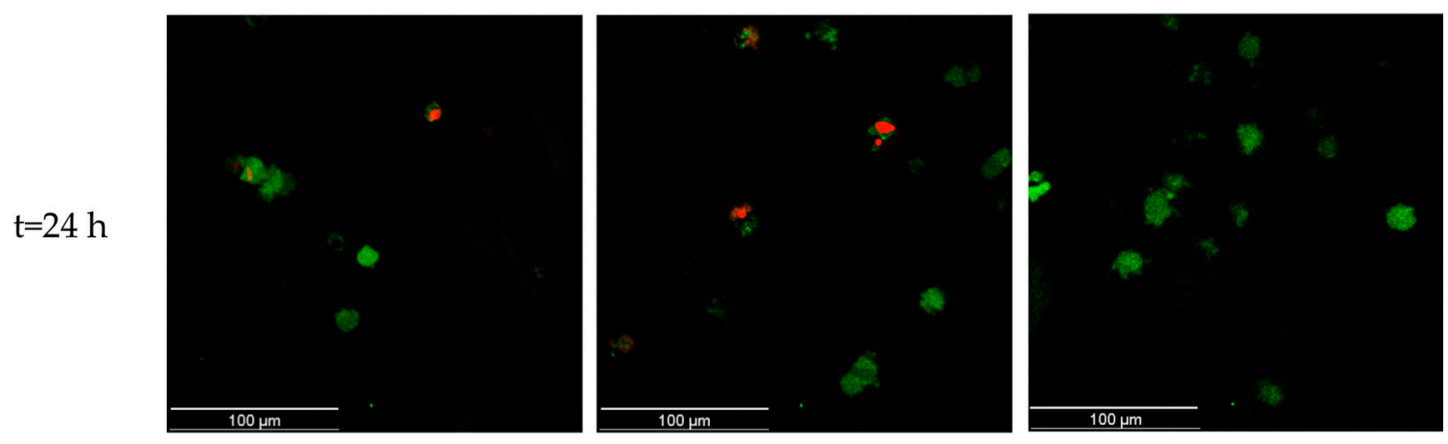

(b)

Figure 7. Representative live/dead (green/red) images for SH-SY5Y cells encapsulated in CH+BGP+SHC hydrogel for $10 \mathrm{~min}(\mathbf{a})$ and $24 \mathrm{~h} \mathrm{(b).} \mathrm{Scale} \mathrm{bar,} 100 \mu \mathrm{m}$.

\section{Discussion}

Although other studies reported the obtainment of thermoresponsive chitosan-based hydrogel by using BGP as gelling agent [21] and the addition of SHC to increase the mechanical properties of the $\mathrm{CH}+\mathrm{BGP}$ system [31], here, we combined for the first time $\mathrm{CH}$ with SHC solution as GA and studied the influence of the BGP and ARG addition on the $\mathrm{CH}+\mathrm{SHC}$ hydrogel properties. Hydrogel solutions flowing freely at RT were successfully obtained after mixing $\mathrm{CH}$ solution with SHC, BGP and ARG solutions. The hydrogel solutions turned into a solid state at $37^{\circ} \mathrm{C}$ due to the decrease of chitosan chain polarity and the increase of BGP hydrophobic interactions with $\mathrm{CH}$ [42]. The hydrogel solutions could all be easily injected into a PBS solution at $37^{\circ} \mathrm{C}$. A sol-gel transition was observed as the temperature increased, showing the hydrogel thermo-responsiveness (see Videos S1, S2, S3 in SI). The inversion tube test results, in agreement with literature, indicated that the gel state of $\mathrm{CH}-\mathrm{SHC}$ systems is reached after a few minutes of incubation at $37^{\circ} \mathrm{C}$ [43]. The addition of an organic salt, BGP, and L-Arg, did not induce any change in the thermoresponsive behavior of the $\mathrm{CH}+\mathrm{SHC}$ system.

One of the most important properties of hydrogels for 3D cell culture is their ability to incorporate large amounts of water, conventionally evaluated by measuring their swelling capability. The SR was almost equal for the different hydrogel formulations, with average values in the range $600-1000 \%$, in perfect agreement with literature results [18], clearly indicating a superabsorbent behavior. As expected, the SR of the herein proposed hydrogel systems was lower than SR values reported for pure $\mathrm{CH}$ 
hydrogel, confirming that BGP, SHC and Arg interact with $\mathrm{CH}$ chain limiting $\mathrm{CH}$ swelling capability [40]. Moreover, though all the three hydrogels presented very high SR values, $\mathrm{CH}+\mathrm{SHC}+\mathrm{BGP}+\mathrm{ARG} \mathrm{SR}$ after 30 min was significantly lower, suggesting a stronger initial interaction among chitosan chains due to the presence of three GAs.

Degradation behavior is another key parameter for the design of 3D hydrogel systems, as it provides an indication of their short and long-term stability during cell culture. The tested hydrogel formulations presented a similar degradation profile, showing a faster weight loss percentage in the first $24 \mathrm{~h}$, without any further increase up to 4 days. The maximum weight loss settled in the range of $25-30 \%$, in agreement with other studies [44]. Samples with SHC+BGP without ARG, however, presented weight loss after $48 \mathrm{~h}$ of $28.5 \pm 1.2 \%$ significantly higher than those of other two hydrogel formulations, indicating the possibility of tuning the degradation profile according to the need, by simply varying the GA solution components.

It is well known that the mechanical properties of cell microenvironment influence cell behavior and functions [45]. From adhesion to differentiation, the most relevant cellular events from early embryogenesis onwards are all, in some way, affected by tissue stiffness [46]. To evaluate the hydrogel bulk stiffness, compression tests have been performed and the results indicated that the addition of BGP induced an increase in the Young modulus in comparison to $\mathrm{CH}$ hydrogels with only SHC, likely due to stronger interactions among chitosan chains occurring in the presence of BGP. Conversely, the presence of ARG does not change the hydrogel mechanical properties in compression mode even if a stabilizing effect has been underlined by swelling test. Interestingly, the three hydrogel formulations provide different Young values in compression at low strain values according to the GA composition but always in the range of most of "soft" biological tissues, i.e., 1-10 KPa [41-46].

Preliminary biological tests have been performed to assess the hydrogel biocompatibility. The indirect test showed that all three hydrogels systems do not release any cytotoxic substance and are highly biocompatible. As a proof of concept, human neuroblastoma cells were encapsulated within the 3D hydrogel: after $24 \mathrm{~h}$, the cells resulted metabolically active in a large number and spatially uniform within the hydrogel, confirming the hydrogel potential for cell encapsulation. Cell morphology was different from cells grown on a traditional culture plate. In particular, cells showed a more rounded shape and tended to form small clusters, probably because of the 3D configuration provide by hydrogel. Cells may need more time to stretch and extend actin filaments across the hydrogel structure [47].

\section{Conclusions}

In the present study, three injectable, thermoresponsive, biocompatible $\mathrm{CH}$-based hydrogels were developed and characterized. The hydrogel sol-gel transition occurred at $37^{\circ} \mathrm{C}$ and, at the gel state, the system presented a physiological $\mathrm{pH}$ compatible with cell encapsulation. The addition of BGP to SHC solutions conferred the $\mathrm{CH}$-based hydrogel system with higher (i) stiffness in compression without any changes in the swelling ratio, (ii) degradation properties and (iii) biocompatibility. The introduction of ARG in the hydrogel system did not alter the overall properties of $\mathrm{CH}$ hydrogels, besides conferring a slightly smaller weigh loss percentage due to an increased stability in cell culture conditions. Further biological experiments will elucidate the role of ARG as metabolic boost in this system, as it was observed previously [38]. Overall, this study suggests that by varying the GA solution composition it may be possible to modulate the physical properties of $\mathrm{CH}$-based hydrogel systems according to the target cell requirements. To the best of our knowledge, no studies have been reported on the bioencapsulation of SH-SY5Y using a thermosensitive $\mathrm{CH}+\mathrm{SHC}+\mathrm{BGP}+\mathrm{ARG}$ injectable hydrogel as 3D cell culture system.

Supplementary Materials: The following are available online at http://www.mdpi.com/2076-3417/10/18/6550/s1, Figure S1, Figure S2, Video S1: $\mathrm{CH}+\mathrm{SHC}+\mathrm{BGP}$ injection at RT, Video S2: $\mathrm{CH}+\mathrm{SHC}+\mathrm{BGP}$ injection in PBS at $37^{\circ} \mathrm{C}$, Video S3: $\mathrm{CH}+\mathrm{SHC}+\mathrm{BGP}$ injection in PBS at $4{ }^{\circ} \mathrm{C}$.

Author Contributions: Conceptualization, F.G., L.M. and A.P.; methodology, A.S.; A.S. hydrogel preparation, swelling and stability tests and cell encapsulation, A.S.; compression tests, result analysis supplementary videos 
and picture acquisition, F.G.; supervision of cell study, contribution to analyze the biological results, V.L.P., A.R. and A.Q; writing-original draft preparation, A.S. and F.G.; writing-review and editing, A.P. and L.M.; supervision, G.G., L.M. and A.Q.; funding acquisition, G.G. All authors have read and agreed to the published version of the manuscript.

Funding: This research was funded by Regione Puglia, Progetto FISR-C.N.R. “Tecnopolo di nanotecnologia e fotonica per la medicina di precisione" - CUP B83B17000010001, and "Tecnopolo per la medicina di Precisione, Regione Puglia"-CUP:B84I18000540002.

Conflicts of Interest: The authors declare no conflict of interest. The funders had no role in the design of the study; in the collection, analyses, or interpretation of data; in the writing of the manuscript, or in the decision to publish the results.

\section{References}

1. Edmondson, R.; Broglie, J.J.; Adcock, A.F.; Yang, L. Three-Dimensional Cell Culture Systems and Their Applications in Drug Discovery and Cell-Based Biosensors. ASSAY Drug Dev. Technol. 2014, 12, $207-218$. [CrossRef] [PubMed]

2. Souza, G.R.; Molina, J.R.; Raphael, R.M.; Ozawa, M.G.; Stark, D.J.; Levin, C.S.; Bronk, L.; Ananta, J.S.; Mandelin, J.; Georgescu, M.-M.; et al. Three-dimensional tissue culture based on magnetic cell levitation. Nat. Nanotechnol. 2010, 5, 291-296. [CrossRef] [PubMed]

3. Huang, Y.-T.; Lai, P.C.; Chiu, T.H. Overexpression of BDNF and TrkB in human bladder cancer specimens. Oncol. Rep. 2010, 24, 1265-1270. [CrossRef]

4. Baharvand, H.; Hashemi, S.M.; Ashtiani, S.K.; Farrokhi, A. Differentiation of human embryonic stem cells into hepatocytes in 2D and 3D culture systems in vitro. Int. J. Dev. Biol. 2006, 50, 645-652. [CrossRef] [PubMed]

5. Chang, T.T.; Hughes-Fulford, M. Monolayer and Spheroid Culture of Human Liver Hepatocellular Carcinoma Cell Line Cells Demonstrate Distinct Global Gene Expression Patterns and Functional Phenotypes. Tissue Eng. Part A 2009, 15, 559-567. [CrossRef] [PubMed]

6. Härmä, V.; Virtanen, J.; Mäkelä, R.; Happonen, A.; Mpindi, J.-P.; Knuuttila, M.; Kohonen, P.; Lötjönen, J.; Kallioniemi, O.; Nees, M. A Comprehensive Panel of Three-Dimensional Models for Studies of Prostate Cancer Growth, Invasion and Drug Responses. PLoS ONE 2010, 5, e10431. [CrossRef] [PubMed]

7. Mitra, M.; Mohanty, C.; Harilal, A.; Maheswari, U.K.; Sahoo, S.K.; Krishnakumar, S. A novel in vitro three-dimensional retinoblastoma model for evaluating chemotherapeutic drugs. Mol. Vis. 2012, 18, 1361-1378. [PubMed]

8. Badylak, S.F.; Freytes, D.; Gilbert, T.W. Extracellular matrix as a biological scaffold material: Structure and function. Acta Biomater. 2009, 5, 1-13. [CrossRef]

9. Hutmacher, D.W. Scaffolds in Tissue Engineering Bone and Cartilage. Biomater. Silver Jubil. Compend. 2000, 21, 175-189.

10. Gasperini, L.; Mano, J.F.; Reis, R.L. Natural polymers for the microencapsulation of cells. J. R. Soc. Interface 2014, 11, 20140817. [CrossRef]

11. Dutta, R.C.; Dutta, A.K. Cell-interactive 3D-scaffold; advances and applications. Biotechnol. Adv. 2009, 27, 334-339. [CrossRef] [PubMed]

12. Hoffman, A.S. Hydrogels for biomedical applications. Adv. Drug Deliv. Rev. 2012, 64, 18-23. [CrossRef]

13. Zhao, W.; Jin, X.; Cong, Y.; Liu, Y.; Fu, J. Degradable natural polymer hydrogels for articular cartilage tissue engineering. J. Chem. Technol. Biotechnol. 2012, 88, 327-339. [CrossRef]

14. Chang, C.; Duan, B.; Cai, J.; Zhang, L. Superabsorbent hydrogels based on cellulose for smart swelling and controllable delivery. Eur. Polym. J. 2010, 46, 92-100. [CrossRef]

15. Lee, J.; Cuddihy, M.J.; Kotov, N.A. Three-Dimensional Cell Culture Matrices: State of the Art. Tissue Eng. Part B Rev. 2008, 14, 61-86. [CrossRef] [PubMed]

16. Buenger, D.; Topuz, F.; Groll, J. Hydrogels in sensing applications. Prog. Polym. Sci. 2012, 37, 1678-1719. [CrossRef]

17. Klouda, L.; Mikos, A.G. Thermoresponsive hydrogels in biomedical applications. Eur. J. Pharm. Biopharm. 2008, 68, 34-45. [CrossRef]

18. Slaughter, B.V.; Khurshid, S.S.; Fisher, O.Z.; Khademhosseini, A.; Peppas, N.A. Hydrogels in Regenerative Medicine. Adv. Mater. 2009, 21, 3307-3329. [CrossRef] 
19. Peppas, N.A.; Hilt, J.Z.; Khademhosseini, A.; Langer, R. Hydrogels in Biology and Medicine: From Molecular Principles to Bionanotechnology. Adv. Mater. 2006, 18, 1345-1360. [CrossRef]

20. Thiele, J.; Ma, Y.; Bruekers, S.M.C.; Ma, S.; Huck, W.T.S. 25th Anniversary Article: Designer Hydrogels for Cell Cultures: A Materials Selection Guide. Adv. Mater. 2013, 26, 125-148. [CrossRef]

21. Zhou, H.; Jiang, L.J.; Cao, P.P.; Li, J.B.; Chen, X. Glycerophosphate-based chitosan thermosensitive hydrogels and their biomedical applications. Carbohydr. Polym. 2015, 117, 524-536. [CrossRef] [PubMed]

22. Gurski, L.A.; Jha, A.K.; Zhang, C.; Jia, X.; Farach-Carson, M.C. Hyaluronic acid-based hydrogels as 3D matrices for in vitro evaluation of chemotherapeutic drugs using poorly adherent prostate cancer cells. Biomaterials 2009, 30, 6076-6085. [CrossRef] [PubMed]

23. Azab, A.K.; Orkin, B.; Doviner, V.; Nissan, A.; Klein, M.; Srebnik, M.; Rubinstein, A. Crosslinked chitosan implants as potential degradable devices for brachytherapy: In vitro and in vivo analysis. J. Control. Release 2006, 111, 281-289. [CrossRef] [PubMed]

24. Ehrbar, M.; Djonov, V.; Schnell, C.; Tschanz, S.; Martiny-Baron, G.; Schenk, U.; Wood, J.; Burri, P.H.; Hubbell, J.A.; Zisch, A.H. Cell-Demanded Liberation of VEGF121From Fibrin Implants Induces Local and Controlled Blood Vessel Growth. Circ. Res. 2004, 94, 1124-1132. [CrossRef]

25. Butcher, J.T.; Nerem, R.M. Porcine aortic valve interstitial cells in three-dimensional culture: Comparison of phenotype with aortic smooth muscle cells. J. Hear. valve Dis. 2004, 13, 478-486.

26. Barralet, J.E.; Wang, L.; Lawson, M.; Triffitt, J.T.; Cooper, P.R.; Shelton, R.M. Comparison of bone marrow cell growth on 2D and 3D alginate hydrogels. J. Mater. Sci. Mater. Electron. 2005, 16, 515-519. [CrossRef]

27. Bhattarai, N.; Gunn, J.; Zhang, M. Chitosan-based hydrogels for controlled, localized drug delivery. Adv. Drug Deliv. Rev. 2010, 62, 83-99. [CrossRef]

28. Elieh-Ali-Komi, D.; Hamblin, M.R. Chitin and Chitosan: Production and Application of Versatile Biomedical Nanomaterials. Int. J. Adv. Res. 2016, 4, 411-427.

29. Cho, J.; Heuzey, M.-C.; Bégin, A.; Carreau, P.J. Physical Gelation of Chitosan in the Presence of $\beta$-Glycerophosphate: The Effect of Temperature. Biomacromolecules 2005, 6, 3267-3275. [CrossRef]

30. Huang, Z.; Yu, B.; Feng, Q.; Li, S. Modification of an Injectable Chitosan Scaffold by Blending with NaHCO3 to Improve Cytocompatibility. Polym. Polym. Compos. 2011, 19, 781-788. [CrossRef]

31. Assaad, E.; Maire, M.; Lerouge, S. Injectable thermosensitive chitosan hydrogels with controlled gelation kinetics and enhanced mechanical resistance. Carbohydr. Polym. 2015, 130, 87-96. [CrossRef] [PubMed]

32. Efron, D.T.; Kirk, S.J.; Regan, M.C.; Wasserkrug, H.L.; Barbul, A. Nitric oxide generation from L-arginine is required for optimal human peripheral blood lymphocyte DNA synthesis. Surgery 1991, 110, 327-334. [PubMed]

33. Greene, J.M.; Feugang, J.M.; Pfeiffer, K.E.; Stokes, J.V.; Bowers, S.D.; Ryan, P.L. L-arginine enhances cell proliferation and reduces apoptosis in human endometrial RL95-2 cells. Reprod. Biol. Endocrinol. 2013, 11, 15. [CrossRef] [PubMed]

34. Rackéf, K.; Warnken, M. L-Arginine Metabolic Pathways !2009-11-28 !2010-03-03 !2010-05-04 ! Open Nitric Oxide J. 2010, 2, 9-19. [CrossRef]

35. Damodaran, V.B.; Bhatnagar, H.; Rubin, D.; Reynolds, M.M. Chapter 6-Nitric oxide donors in nerve regeneration. In Nitric Oxide Donors; Seabra, A.B., Ed.; Academic Press: Cambridge, MA, USA, 2017; pp. 141-168.

36. Shi, H.P.; Wang, S.M.; Zhang, G.X.; Zhang, Y.J.; Barbul, A. Supplemental l-arginine enhances wound healing following trauma/hemorrhagic shock. Wound Repair Regen. 2007, 15, 66-70. [CrossRef]

37. Izzo, D.; Palazzo, B.; Scalera, F.; Gullotta, F.; Lapesa, V.; Scialla, S.; Sannino, A.; Gervaso, F. Chitosan scaffolds for cartilage regeneration: Influence of different ionic crosslinkers on biomaterial properties. Int. J. Polym. Mater. 2018, 68, 936-945. [CrossRef]

38. Scialla, S.; Barca, A.; Palazzo, B.; D’Amora, U.; Russo, T.; Gloria, A.; De Santis, R.; Verri, T.; Sannino, A.; Ambrosio, L.; et al. Bioactive chitosan-based scaffolds with improved properties induced by dextran-grafted nano-maghemite and 1 -arginine amino acid. J. Biomed. Mater. Res. Part A 2019, 107, 1244-1252. [CrossRef]

39. Nitti, P.; Gallo, N.; Palazzo, B.; Sannino, A.; Polini, A.; Verri, T.; Barca, A.; Gervaso, F. Effect of 1-Arginine treatment on the in vitro stability of electrospun aligned chitosan nanofiber mats. Polym. Test. 2020, 91, 106758. [CrossRef] 
40. Puppi, D.; Migone, C.; Morelli, A.; Bartoli, C.; Gazzarri, M.; Pasini, D.; Chiellini, F. Microstructured chitosan/poly( $\gamma$-glutamic acid) polyelectrolyte complex hydrogels by computer-aided wet-spinning for biomedical three-dimensional scaffolds. J. Bioact. Compat. Polym. 2016, 31, 531-549. [CrossRef]

41. Vedadghavami, A.; Minooei, F.; Mohammadi, M.H.; Khetani, S.; Kolahchi, A.R.; Mashayekhan, S.; Sanati-Nezhad, A. Manufacturing of hydrogel biomaterials with controlled mechanical properties for tissue engineering applications. Acta Biomater. 2017, 62, 42-63. [CrossRef]

42. Deng, A.; Kang, X.; Zhang, J.; Yang, Y.; Yang, S. Enhanced gelation of chitosan/ $\beta$-sodium glycerophosphate thermosensitive hydrogel with sodium bicarbonate and biocompatibility evaluated. Mater. Sci. Eng. C 2017, 78, 1147-1154. [CrossRef] [PubMed]

43. Ke, X.; Li, M.; Wang, X.; Liang, J.; Wang, X.; Wu, S.; Long, M.; Hu, C. An injectable chitosan/dextran/ $\beta$ -glycerophosphate hydrogel as cell delivery carrier for therapy of myocardial infarction. Carbohydr. Polym. 2020, 229, 115516. [CrossRef] [PubMed]

44. Ceccaldi, C.; Assaad, E.; Hui, E.; Buccionyte, M.; Adoungotchodo, A.; Lerouge, S. Optimization of Injectable Thermosensitive Scaffolds with Enhanced Mechanical Properties for Cell Therapy. Macromol. Biosci. 2017, 17, 1600435. [CrossRef] [PubMed]

45. Chen, J.; Irianto, J.; Inamdar, S.; Pravincumar, P.; Lee, D.A.; Bader, D.; Knight, M.M. Cell Mechanics, Structure, and Function Are Regulated by the Stiffness of the Three-Dimensional Microenvironment. Biophys. J. 2012, 103, 1188-1197. [CrossRef] [PubMed]

46. Guimarães, C.F.; Gasperini, L.; Marques, A.P.; Reis, R.L. The stiffness of living tissues and its implications for tissue engineering. Nat. Rev. Mater. 2020, 5, 351-370. [CrossRef]

47. Aubin, H.; Nichol, J.W.; Hutson, C.B.; Bae, H.; Sieminski, A.L.; Cropek, D.M.; Akhyari, P.; Khademhosseini, A. Directed 3D cell alignment and elongation in microengineered hydrogels. Biomaterials 2010, 31, 6941-6951. [CrossRef]

(C) 2020 by the authors. Licensee MDPI, Basel, Switzerland. This article is an open access article distributed under the terms and conditions of the Creative Commons Attribution (CC BY) license (http://creativecommons.org/licenses/by/4.0/). 